\title{
Stages of Individuals and the Composition of States ${ }^{1}$ E. MATTHEW HUSBAND
}

\begin{abstract}
Whether a stative predicate licenses an existential interpretation of its subject (EIS) depends in part on the type of object it has. While previous theories have related this to the object's ability to function as a topic, this paper presents evidence that the quantized/homogeneous distinction between objects better captures EIS and proposes an event composition analysis of EIS for (transitive) stative predicates. This analysis points to the aspectual nature of EIS and also illuminates other aspectual behaviors of stage-level/individual-level states.
\end{abstract}

\section{Introduction}

Since at least Verkuyl (1972), analyses of the role played by arguments in event structure have lead to a productive research program investigating how certain aspectual properties of events are compositionally determined. Central to this program has been the relationship between the verb and its object. This is seen most clearly in the licensing of telicity in eventive predicates, where the acceptability of in an hour, which indicates the availability of a telic interpretation, changes depending on the type of object as shown in (1) and (2).
(1) a. John built this house
in six months.
b. The students solved these problems in an hour.
(2) a. John built houses *in six months.
b. The students solved problems *in an hour.

A similar observation has also been made for stative predicates. As shown in (3) and (4), changes in a stative's object affect, among other things, the availability of an existential interpretation of a subject (EIS), a property typically associated with the distinction between stage-level and individual-level

\footnotetext{
${ }^{1}$ I would like to thank Marcin Morzycki, Alan Munn, Cristina Schmitt, Alan Beretta, Polly Jacobson, Emma Cunningham, and Terje Lohndal for their suggestions and comments on earlier drafts of this work. Thanks also to the audiences of GLOW and SALT for their interest and feedback.
} 
predicates (Fernald, 1994, 2000). ${ }^{2}$ Thus, much as the telicity of events is compositionally determined, the stage-level/individual-level behavior of states is also compositionally determined.

(3) a. Monkeys live in these trees.

b. Tycoons own this bank.

a. Monkeys live in trees.

b. Tycoons own banks.

While the observed effect of objects on the interpretation of telicity has produced a wide range of research, the same observation for existential interpretation has received less focus. In this paper I explore the effects of objects on the interpretation of states and argue that these Object Effects, as I will refer to them, reveal a compositional process in stative predicates that is normally concealed. In particular, I argue that the quantity of an object, not its topicality, affects the availability of EIS, suggesting that the availability of EIS of stative predicates is aspectual in nature and that the interpretation of stative and eventive predicates follow from similar compositional paths.

This paper is laid out as follows: In Section 2 I review several interpretive properties found in stative predicates, highlighting the presence of Object Effects in transitive stative predicates. I then discuss two competing analyses of Object Effects in Section 3, topic requirement vs. event composition, and examine data in favor of an event composition analysis in Section 4. Section 5 discusses the consequences of adopting an event composition analysis by exploring the aspectual nature of existential interpretation. This provides a background for the particular event composition analysis given in Section 6. I then briefly discuss other aspectual phonemena of stative predicates in light of an event composition analysis in Section 7 before offering some conclusions in Section 8.

\section{State interpretation}

One distinction which holds within stative predicates is that between stagelevel and individual-level predicates. Central to our discussion here is the

\footnotetext{
${ }^{2}$ My primary concern in this paper is the availability of existential interpretations. As such, I will ignore the equally interesting issue of the availability of generic interpretations in these sentences. Judgments will only be given concerning EIS, with a * indicating that EIS is judged to be unavailable and a ? indicating that EIS is judged to be difficult but available.
} 
ability of stage-level and individual-level states to license an existential interpretation of their subject. This effect can be seen in the interpretation of a variety of weak DPs (Carlson, 1977; Kratzer, 1995). For instance (5a) can mean that there are available firemen while (5b) cannot mean that there are altruistic firemen. Similarly, (6a) refers to the firemen as being several in number while (6b) refers to several out of all of the firemen. Finally, (7a) is about an individual fireman while (7b) is about firemen as a kind. This paper focuses on the interpretative contrast in bare plurals in (5), though the availability of existential interpretation may be diagnosed with any of these contrasts.

(5) a. Firemen are available.

b. Firemen are altruistic.

(6) a. Several firemen are available.

(cardinal)

b. Several firemen are altruistic.

(partitive)

(7) a. A fireman is available.

(individual)

b. A fireman is altruistic.

(kind)

Stage-level and individual-level states also contrast in more straightforwardly aspectual terms. Unlike stage-level states, individual-level states in the past tense often trigger a strong inference that their subject is dead (Kratzer, 1995; Magri, 2009; Mittwoch, 2007; Musan, 1995, 1997; Percus, 1997). This lifetime effect can be seen in the contrast between (8a) and (8b).

(8) a. Gregory was available. $\chi_{\rightarrow}$ Gregory is dead.

b. Gregory was altruistic. $\leadsto$ Gregory is dead.

Individual-level states also place restrictions on temporal modification which are not found for stage-level states, blocking most temporal modifiers (Chierchia, 1995; Kratzer, 1995; Maienborn, 2004; Percus, 1997). The contrast between (9a) and (9b) is typical of the restriction imposed by individuallevel states, where $(9 \mathrm{~b})$ can only be interpreted with altruism being a property of John that varies day to day.

(9) a. John was available yesterday.

b. \#John was altruistic yesterday.

The two central questions to be addressed here are why stage-level and individual-level states have the interpretations they do and how a speaker knows when a predicate is stage-level or individual-level. Most theories assume, at least implicitly, that predicates themselves are categorized in terms 
of stage-level or individual-level, leaving open what properties, if any, a speaker uses to derive these categories. Certainly for the adjectival predicates above the relevant properties which categorize their states as stage-level or individuallevel are not directly evident and may appear to be idiosyncratic ${ }^{3}$ however, the stage-level/individual-level status of verbal predicates provides a more transparent case which reveals how a predicate's stage-level/individual-level behavior is derived from its underlying constituent properties.

\subsection{Objects in states}

Returning to the contrast in (3) and (4), we see that the type of object affects the stage-level/individual-level behavior of a verbal predicate: demonstrative objects license an EIS, while bare plural objects do not license an EIS. I will refer to this phenomenon as Object Effects. Further examples are given in (10) and (11).

(10) a. Monkeys live in this tree.

b. Smart kids like these stories.

c. Brown boxes contain these marbles.

a. Monkeys live in trees.

b. Smart kids like stories.

c. Brown boxes contain marbles.

Object Effects also appear in the more straightforwardly aspectual interpretations of stage-level/individual-level states. A demonstrative object weakens the inference to a subject's death, as in (12a), while a bare plural object gives rise to a strong inference of the subject's death, as in (12b).

(12) a. Those monkeys lived in this cage. $\not \rightarrow$ Those monkeys are dead.
b. Those monkeys lived in cages. $\leadsto$ Those monkeys are dead.

Similarly, temporal modification of a verbal predicate with a demonstrative object is fairly unrestricted, as in (13a). This is not the case for verbal predicates with bare plural objects which carry the restriction on temporal

\footnotetext{
${ }^{3}$ See Husband (2010) for an analysis of the stage-level/individual-level behavior of adjectival predicates which argues that they too are compositionally determined in the spirit of the proposal found here.
} 
modifiers, as in (13b). The only interpretation of (13a) available is one in which the kids' general story-liking varies from day to day.

\section{(13) a. The kids liked this story yesterday. b. \#The kids liked stories yesterday.}

Object Effects, therefore, affect a stative predicate's stage-level/individuallevel behavior. Stative verbs with demonstrative objects give rise to stagelevel states and stative verbs with bare plural objects give rise to individuallevel states. At issue then is what property of demonstrative and bare plural objects yields stage-level and individual-level states, respectively, as this will provide insight to the theory of stage-level/individual-level states.

\section{Competing analyses}

\subsection{Requiring topics}

Recent accounts of Object Effects have focused on information structure constraints. These accounts derive Object Effects from two proposals. First, every sentence is required to have a topic (Jäger, 2001). Second, a topic is presupposed and thus cannot receive an existential interpretation. So for an argument to receive an existential interpretation, it cannot be a topic. Often, it is the subject of a sentence that satisfies the topic requirement, blocking it from receiving an existential interpretation. However, topic requirement theories have argued that Object Effects occur because the object is acting as the topic of the sentence. When a demonstrative object, for instance, is acting as the topic as in (3) and (10), the subject is no longer required to satisfy the topic requirement, allowing it to receive an existential interpretation and introducing a new discourse referent (Heycock, 1994; Jäger, 2001; Lee, 1996).

More recently, Kratzer and Selkirk (2007) proposed that the requirement of a syntactically represented topic accounts for Object Effects. Using evidence from scrambling in German, they argue that the topic in (14a) is the scrambled discourse-given object dieses Haus 'this house'. Since the object is acting as the topic, the subject Maffiosi 'mafia members' may remain low and receive an existential interpretation. However, the topic in (15a) can only be the subject Maffiosi 'mafia members', so the subject Maffiosi 'mafia members' must raise to topic position, and is prevented from receiving an existen- 
tial interpretation. ${ }^{4}$ The structures for these two cases are given in (14b) and (15b), respectively.

(14) a. Ich weiss, dass dieses Haus Maffiosi besitzen.

I know that this house mafia.members own 'I know that mafia members own this house.'

b. [CP [TopP dieses Haus [TP [vP Maffiosi $\left[{ }_{V} t_{V}\right]$ besitzen $_{V}+v$ ] T ] Top ] ]

a. Ich weiss, dass Maffiosi Häuser besitzen.

$(*$ EIS $)$

I know that mafia.members houses own

'I know that mafia members own houses.'

b. [CP [TopP Maffiosi $i_{i}\left[\mathrm{TP}_{i}\left[\mathrm{vp}_{i} \mathrm{t}_{i \mathrm{vP}}\right.\right.$ Häuser besitzen $\mathrm{V}$ ] v ] $\left.\mathrm{T}\right]$ Top ] ]

In addition to this evidence, scrambling of a weak object such as the bare plural Häuser 'houses' in (16) leads to degraded judgments.

(16)??Ich weiss, dass Häuser Maffiosi besitzen.

I know that houses mafia.members own

Topic requirement theories like Kratzer and Selkirk (2007) predict that EIS is linked to the ability of the object to function as a topic. To be a topic, the object must be strong since weak objects cannot be topics (Jäger, 2001). Therefore, topic requirement theories predict that the weak/strong distinction governs the availability of EIS: demonstrative objects are strong and can license EIS; bare plural objects are weak and cannot license EIS.

\subsection{Event composition}

As initially introduced, the availability of EIS in stative predicates bares a striking resemblance to the alternation of telicity in eventive predicates. As noted above, demonstrative objects yield telic interpretations of eventive predicates, as in (1), while bare plural objects yield atelic interpretations of eventive predicates, as in (2).

Discussing observations like these on eventive predicates, Verkuyl (1972) proposed an event composition theory in which a specified quantity object

\footnotetext{
${ }^{4}$ Kratzer and Selkirk (2007) also observe that an accent on the predicate is related to EIS. In (14a), the predicate can be deaccented, but in (15a), the predicate must receive a pitch accent.
} 
yields a telic interpretation and an unspecified quantity object yields an atelic interpretation. Since then, research has attempted to characterize both the types of objects which affect telicity and the way these objects enter into the composition of the predicate. Concerning different types of objects, a rich literature has argued that quantity plays an important distinction: quantized objects yield telic interpretations and homogeneous objects yield atelic interpretations (Borer, 2005a,b; Kiparsky, 1998; Krifka, 1989, 1992, 1998; Verkuyl, 1993). ${ }^{5}$

For example, quantized objects like those in (17a) are not cumulative. Given the union of $a$ house and a house, one no longer has something that is $a$ house, but instead, something that is two houses. Homogenous objects like those in (17b), however, are cumulative. Given the union of puzzles and puzzles, one still has something that is puzzles. Eventive predicates which have these as objects take on their quantity. So an event with a quantized object is a quantized event; the event that comes from the union of build a house and build a house is no longer an event that is build a house, but an event of building two houses. An event with a homogeneous object is a homogeneous event; the event that comes from the union of solve puzzles and solve puzzles is still an event of solve puzzles. Note that this affects their telicity. Events with quantized objects like (18a) are telic, while events with homogeneous objects like (18b) are atelic.

(17) a. a house; two puzzles

b. houses; puzzles

(18) a. build a house; solve two puzzles in two months/hours

b. build houses; solve puzzles *in two months/hours

\footnotetext{
${ }^{5} \mathrm{I}$ am assuming the definitions of quantity found in Borer (2005a,b) which distinguish between quantized and homogeneous, given in (i).

(i) a. Quantized: $\mathrm{P}$ is quantity iff $\mathrm{P}$ is not homogeneous.

b. Homogeneous: $\mathrm{P}$ is homogeneous iff $\mathrm{P}$ is cumulative and divisive.

i. $\quad \mathrm{P}$ is cumulative iff $\forall x, y[P(x) \& P(y) \rightarrow P(x \cup y)]$ $\mathrm{P}$ is cumulative iff for all $\mathrm{x}$ and $\mathrm{y}$ with property $\mathrm{P}$, the union of $\mathrm{x}$ and $\mathrm{y}$ also has property $\mathrm{P}$.

ii. $\mathrm{P}$ is divisive iff $\forall x[P(x) \rightarrow \exists y[P(y) \& y<x] \& \forall x, y[P(x) \& P(y) \& y<$ $x \rightarrow P(x-y)]$ ]

$\mathrm{P}$ is divisive iff for all $\mathrm{x}$ with property $\mathrm{P}$ there is a proper part $\mathrm{y}$ of $\mathrm{x}$ which also has property $\mathrm{P}$, and for all $\mathrm{x}$ and $\mathrm{y}$ with property $\mathrm{P}$ if $\mathrm{y}$ is a proper part of $\mathrm{x}$ then the subtraction of $\mathrm{y}$ from $\mathrm{x}$ also has property $\mathrm{P}$.
} 
Event composition theories, therefore, propose that telicity is linked to the quantity of the object. If the resemblance between EIS and telicity is more than a coincidence, event composition theories would predict that the quantity of objects governs Object Effects as well: demonstrative objects are quantized and license EIS; bare plural objects are homogeneous and do not license EIS.

\section{Objects effects revisited}

Topic requirement theories and event composition theories make different predictions about which types of objects license EIS. Topic requirement theories predict that EIS depends on the weak/strong distinction of objects. Event composition theories predict that EIS depends on the quantized/homogeneous distinction of objects. However, the literature on Object Effects has not examined data which would distinguish between these two theories. Both theories predict that mass noun and bare plural objects will not license EIS and that strong determiners and strong quantifiers will license EIS. The theories differ, however, on the behavior of bare numeral, weak determiner, and weak quantifier objects. Topic requirement theories predict that these object types will not license EIS because they are all weak. Event composition theories predict that these object types will license EIS because they are all quantized. Examples (19-21) test these critical cases. ${ }^{6}$

\footnotetext{
${ }^{6}$ An anonymous reviewer noted that some predicates with quantized objects, such as (ia), continue to resist EIS. For many of these cases, contexts like that given in (ib) reveal their ability to admit an EIS.
}

(i) a. Italians love Pavarotti.

b. Attendees at the World Music Awards this year are pulling for a variety of different singers. Italians love Pavarotti.

The reviewer also pointed out other resistive cases containing modifiers like best in (iia) and relative clauses in (iib). While this paper does not not address cases involving modification, I note that these examples are reminiscent of those in Bhatt (1999) and, thus, may have modal properties interacting with the acceptability of an EIS.

(ii) a. Millionaires live in the best mansions.

b. Tycoons own the house they live in. 
(19) Bare Numeral Objects

a. Monkeys live in three trees.

b. Tycoons own two banks.

(20) Weak Determiner Objects

a. Monkeys live in a tree.

b. Tycoons own a bank.

(21) Weak Quantifier Objects

a. Monkeys live in several trees.

b. Tycoons own many banks.

Summarizing the observations above, weak objects that are quantized can, in fact, license EIS. Bare numeral and weak determiner objects are generally less acceptable, though EIS is possible, ${ }^{7}$ and weak quantifier objects license EIS without difficulty. ${ }^{8}$ This pattern supports event composition theories over topic requirement theories. Given this result, the availability of EIS appears to be aspectual in nature, raising several questions: How is existential interpretation aspectual, and why does the quantity of objects affect its availability? The next two sections seek to address these questions.

\section{The aspectual nature of existential interpretation}

At their heart, event composition theories are theories which derive the properties of eventualities from their underlying part structure. The relationship between an event's part structure and telicity is now well understood. Quantized events are telic because they can be counted/measured out. Homogeneous events are atelic because they cannot be counted/measured out. Since

\footnotetext{
${ }^{7}$ Contexts like those in (i) bring out EIS in these marginal examples. Also, a list presentation improves their acceptability (Schmitt, 1996). See Fernald (2000), Glasbey (1997), and Husband (2010) for some discussion on the role of context in licensing EIS.

(i) a. Monkey Context: "Behind my house is mangrove forest."

b. Tycoon Context: "In this city there are over 50 privately owned financial institutions."

(ii) a. Monkeys live in three trees, bats live in two caves, and weasels live in one burrow.

b. Tycoons own a bank, lawyers own a firm, and hippies own a coffee shop.
}

${ }^{8}$ See Husband (forthcoming) for cross-linguistic evidence and additional data which seeks to control for the weak/strong interpretations of weak objects. 
the availability of EIS is also related to quantity, we want to address what the relationship is between a state's part structure and EIS.

To address this relationship, we must first take a short detour into the domain of individuals. Carlson (1977) proposed that the domain of individuals has two different sorts: a stage of an individual, "roughly, a spatially and temporally bounded manifestation of something"; and an individual, "that whatever-it-is that ties a series of stages together to make them stages of the same thing" (68). ${ }^{9}$ He further proposes that stage-level states take stages as their arguments and individual-level states take individuals as their arguments. Under this system, stage-level states are about some stage of an individual, and individual-level states are about an individual itself. Though not explicit in Carlson (1977), it is clear that a stage is an inherently aspectual notion. Stages provide the internal spatiotemporal constitution of an individual. Thus much like events, we can think of individuals as having aspectual parts.

What, then, does this tell us about the availability of EIS in stative predicates and how does this related to Object Effects? Consider the role of quantity in determining the behavior of a stative predicate. Stative predicates which license EIS are those which have quantized objects. As stage-level predicates, they are also those which Carlson proposes to be about a stage of an individual. Suppose then that what a stage of an individual is is a quantized representation of that individual. As a bounded spatiotemporal manifestation, a stage of an individual meets the requirements of being quantized. Similar to the failure of cumulativity in quantized events, the stage that comes from the union of John was available and John was available is not necessarily a stage of John was available, but instead may be two stages of John being available, as they may select two different stages of John that do not overlap. ${ }^{10}$ Finally, since a quantized stage of an individual is a spatiotemporally bounded manifestation of an individual, its existence can be inferred. Thus states with quantized objects also have subjects represented as a quantized stage and this licenses an EIS.

On the other hand, stative predicates which do not license EIS are those which have homogeneous objects. They are also those which Carlson pro-

\footnotetext{
${ }^{9}$ Carlson (1977) also discussed objects and kinds as different sorts in the domain of individuals, but put them together under the term individual. Since the distinction between objects and kinds is not directly relevant, I will only distinguish between stages and individuals.

${ }^{10}$ The predicates available and altruistic are used here to help identify a stage of John and the individual John, respectively.
} 
poses to be about an individual since they are individual-level predicates. Remembering that individuals are composed of stages, suppose that the way an individual is represented is as a homogeneous collection of the stages of an individual. Looking at cumulativity, the union of John was altruistic and John was altruistic can only be the same John being altruistic. Unlike the case above, John qua individual is the series of stages that make up John, and there is no way to select two different individuals John. Finally, since homogeneous stages of an individual are not spatiotemporally bounded, existence cannot inferred. ${ }^{11}$ Thus states with homogeneous objects also have subjects represented as homogeneous stages and this fails to license an EIS.

The aspectual nature of the availability of EIS is seen in the different requirements a stative predicate places on the internal spatiotemporal structure of its subject. Stage-level states predicate over a quantized stage of an individual, while individual-level states predicate over homogeneous stages of an individual. ${ }^{12}$ The question remaining is why the quantity of objects is tightly correlated with these requirements, i.e. how are these requirements to be derived?

\section{Deriving stage-level and individual-level states}

To address the relationship between the quantity of the object of a stative predicate and the availability of EIS, I will first address how the predicate itself inherits quantity from its object. Once that is established, I will turn to how a stative predicate's quantity is passed on to its subject.

\footnotetext{
${ }^{11}$ Previous work has proposed a similar rationale for the availability of EIS. McNally (1998), for instance, suggests that stage-level predicates are location dependent and allow an existential inference, while individual-level predicates generalize over generic locations of an individual which blocks an existential inference because generalizing whether a predicate holds for an individual over generic locations requires that individual to be presupposed. Generalizing over generic locations appears very similar to generalizing over a homogeneous collection of stages of an individual. Similarly, Chierchia (1998) suggests that we should use parts of individuals across worlds to understand genericity.

${ }^{12}$ Note also that under the theory being developed here, predicates only select for stages of individuals as the sortal type of their arguments, simplifying the sortal requirements of predicates. Individuals themselves are only indirectly accessed through a homogeneous predicate. This reverses the proposal found in Carlson (1977); DPs denote stages and not individuals.
} 


\subsection{The composition of stative predicates}

In a recent proposal on the composition of events, Kratzer (2004) derives the telicity of eventive predicates through the meaning of the accusative case. Accusative case enters into the composition of the predicate as shown in (22) and, following Krifka (1998), enforces a mapping to events through the denotation given in (23). ${ }^{13,14}$

$$
\llbracket \mathrm{ACC} \rrbracket=\lambda R_{\langle e,\langle s, t\rangle\rangle} \lambda x \lambda e[R(x)(e) \& \underbrace{\forall x^{\prime}\left[x^{\prime} \leq x \rightarrow \exists e^{\prime}\left[e^{\prime} \leq e \& R\left(x^{\prime}\right)\left(e^{\prime}\right)\right]\right]}_{\text {Mapping to Events }}
$$

Through the mapping to events encoded in the semantics of case, the event argument inherits the part structure of its object. This mapping derives a quantized event when the object is quantized and derives a homogeneous event when the object is homogeneous. Quantized events, in turn, are interpreted as telic, and homogeneous events are interpreted as atelic.

Extending this analysis to also allow states to participate in this mapping, I propose that the state argument also inherits the part structure of its object.

\footnotetext{
${ }^{13}$ Semantic types: individuals, $e$; eventualities, $s$; and propositions, $t$. Variables: over individuals, $x$ and $y$; over eventualities, $e$ for events and $s$ for states. Compositional operations: Function Application and Predicate Abstraction.

${ }^{14}$ For clarity of exposition, I suppress Kratzer's measure $f$ in this paper. For Kratzer, measure $f$ indicates "the assumption that there is some general cognitive mechanism that determines a range of functions that map the referents of certain direct objects into concrete or abstract 'measuring rods' that are associated with those referents in some way or other" (394). Certainly some mileage could be gained by considering which "measuring rods" are applicable in stative predicates, but as this is not the main focus here, I set it aside for future consideration.
} 
Examples of a quantized stative predicate and a homogeneous stative predicate are given in (24) and (25) respectively.

$$
\begin{aligned}
& \llbracket \text { own this bank } \rrbracket=\lambda s\left[\text { own } ( \text { this-bank } ) ( s ) \& \forall x ^ { \prime } \left[x^{\prime} \leq \text { this-bank } \rightarrow\right.\right. \\
& \left.\left.\exists s^{\prime}\left[s^{\prime} \leq s \& \operatorname{own}\left(x^{\prime}\right)\left(s^{\prime}\right)\right]\right]\right] \\
& \llbracket \text { own banks } \rrbracket=\lambda s\left[\text { own } ( \text { banks } ) ( s ) \& \forall x ^ { \prime } \left[x ^ { \prime } \leq \text { banks } \rightarrow \exists s ^ { \prime } \left[s^{\prime} \leq\right.\right.\right. \\
& \left.\left.\left.s \& \text { own }\left(x^{\prime}\right)\left(s^{\prime}\right)\right]\right]\right]
\end{aligned}
$$

For a quantized state, the mapping to events derives a quantized state because its object is quantized. For (24), the demonstrative object this bank is quantized and thus there is no proper part of this bank which is also this bank. The meaning of accusative maps the quantized part structure of this bank to the part structure of the state $s$ by stating the existence of substates $s^{\prime}$ which are ownings of the proper parts of this bank. Since this bank has only one part, namely itself, the only substate $s^{\prime}$ asserted is the one identical with the state $s$.

For a homogeneous state, the mapping to events derives a homogeneous state because its object is homogeneous. For (25), the bare plural object banks is homogeneous and has proper parts which are also banks. ${ }^{15}$ The meaning of accusative case maps the homogeneous part structure of banks to the part structure of the state $s$ by stating the existence of substates $s^{\prime}$ which are ownings of the proper parts of banks. Since banks has unbounded numbers of proper parts which are also banks, an unbounded number of substates $s^{\prime}$ is asserted.

Under this analysis, stative and eventive predicates follow identical compositional paths. Both inherit the part structure of their object through a mapping to events. However, stative and eventive predicates differ in their in-

\footnotetext{
${ }^{15}$ This analysis assumes that both mass nouns and bare plurals denote homogeneous representations which are cumulative and divisive. Mass nouns clearly fit this profile, denoting semilattice structures with no minimal or maximal element (Link, 1998). While some argue that bare plurals require minimal elements (i.e. atoms), Borer (2005a) observes that the interpretation of bare plurals in sentences like (i) do not require minimal elements. For instance, (ic) can be true even if after half an hour only a collection of arcs resulted without a single circle being completed.
}

(i) a. Kim ate apples for an hour.

b. Pat built houses for three months.

c. John drew circles for half an hour. 
14

terpretation. In particular, stative predicates affect the interpretation of their subject, a matter I turn to presently.

\subsection{Introducing the subject}

Following Kratzer (1996), I assume that the external argument is introduced by a functional head, Voice. Kratzer proposed that the denotations of Voice heads are composed with meaning of a predicate by the compositional rule of Event Identification, given in (26). This rule adds conditions to the eventuality, as shown in (27). Kratzer also proposed that Event Identification is constrained by aktionsart: the predicates it is combining must be of the same aktionsart type. This, she noted, constrains the relationship between the external argument's $\theta$ role and eventive and stative predicates. Eventive predicates have Agent external arguments, and stative predicates have Holder external arguments.

$$
\begin{array}{llll}
\text { Event Identification: } & & & \\
f_{\langle e,\langle s, t\rangle\rangle} & g_{\langle s, t\rangle} & \rightarrow & h_{\langle e,\langle s, t\rangle\rangle} \\
\lambda x \lambda e[f(x)(e)] & \lambda e[g(e)] & \rightarrow & \lambda x \lambda e[f(x)(e) \& g(e)]
\end{array}
$$

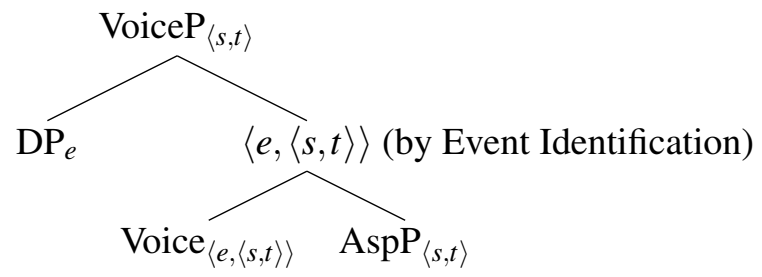

As discusses above, the availability of EIS is related to the quantity of the predicate. To capture this relationship, I propose extending Kratzer's stative Voice head to include a mapping to individuals, given in (28) (Krifka, 1998). ${ }^{16}$ This stative Voice head performs two roles. First, as in Kratzer

\footnotetext{
${ }^{16}$ Examples like those in (i) and (ii) suggest that a similar mapping appears to also be needed in events, given in (iii). Note that it is a mapping to events as the part structure of the subject affects the part structure of the event.

(i) a. Settlers crossed the desert for years.

b. Two hundred settlers crossed the desert \#for years.

(ii) a. Water leaked through the roof for an hour.

b. A gallon of water leaked through the roof \#for an hour.
} 
(1996), it relates the external argument to the eventuality via its holder $\theta$ role. Second, it maps the part structure of the eventuality to the subject's part structure, asserting that for every substate, there is a part of the subject which is the holder of that substate.

$$
\llbracket \operatorname{Voice}_{S} \rrbracket=\lambda x \lambda s[\operatorname{Holder}(x)(s) \& \underbrace{\forall s^{\prime}\left[s^{\prime} \leq s \rightarrow \exists x^{\prime}\left[x^{\prime} \leq x \& \operatorname{Holder}\left(x^{\prime}\right)\left(s^{\prime}\right)\right]\right]}_{\text {Mapping to Individuals }}]
$$

To given an example, (29) and (30) follow from (24) and (25), respectively. In both cases, the stative Voice head introduces the subject as the holder of the state and also introduces a mapping to individuals. The difference between them comes directly from the way the quantity of their object affects the mappings.

【Tycoons own this bank $\rrbracket=\lambda s\left[\right.$ Holder(Tycoons) $(s) \& \forall s^{\prime}\left[s^{\prime} \leq s \rightarrow\right.$ $\exists x^{\prime}\left[x^{\prime} \leq\right.$ Tycoons \& Holder $\left.\left.\left(x^{\prime}\right)\left(s^{\prime}\right)\right]\right] \&$ [own(this-bank) $(s) \& \forall x^{\prime}\left[x^{\prime} \leq\right.$ this-banks $\rightarrow \exists s^{\prime}\left[s^{\prime} \leq s \&\right.$ own $\left.\left.\left.\left.\left(x^{\prime}\right)\left(s^{\prime}\right)\right]\right]\right]\right]$

(30) $\llbracket$ Tycoons own banks $\rrbracket=\lambda s\left[\right.$ Holder(Tycoons) $(s) \& \forall s^{\prime}\left[s^{\prime} \leq s \rightarrow\right.$ $\exists x^{\prime}\left[x^{\prime} \leq\right.$ Tycoons \& Holder $\left.\left.\left(x^{\prime}\right)\left(s^{\prime}\right)\right]\right] \&[$ own (banks $)(s) \& \forall x^{\prime}\left[x^{\prime} \leq\right.$ banks $\rightarrow \exists s^{\prime}\left[s^{\prime} \leq s \&\right.$ own $\left.\left.\left.\left.\left(x^{\prime}\right)\left(s^{\prime}\right)\right]\right]\right]\right]$

For quantized states like (29), the state consists of a single state, an owning of this bank, as discussed above for (24). The mapping to individuals asserts the existence of a stage of the subject for each substate, but since there is only one substate, namely, the state itself, only one stage of the subject is asserted as the holder of that state. Since this is a quantized stage, it is spatiotemporally bounded and EIS is licensed.

For homogeneous states like (30), the state consists of a homogeneous part structure of substates, each an owning of banks, as discussed above for (25). The mapping to individuals asserts the existence of a stage, i.e. a part, of the subject for each of these substates such that that stage of the subject is the holder of that substate. Since this is a homogeneous set of stages, no spatiotemporal bound is given and EIS is not licensed.

(iii) $\llbracket \operatorname{Voice}_{E} \rrbracket=\lambda x \lambda e[\operatorname{Agent}(x)(e) \& \underbrace{\forall x^{\prime}\left[x^{\prime} \leq x \rightarrow \exists e^{\prime}\left[e^{\prime} \leq e \& \operatorname{Agent}\left(x^{\prime}\right)\left(e^{\prime}\right)\right]\right]}_{\text {Mapping to Events }}]$ 
By extending Kratzer's stative Voice head to include a mapping to individuals, the subject of a stative predicate inherits the quantity of that predicate. EIS then follows from whatever quantity the subject has inherited. Below, I provide some evidence for Voice in stative predicates and the addition of a mapping to individuals to the stative Voice head through an investigation of nominalizations.

\subsubsection{Evidence for Voice in stative predicates}

In addition to introducing the external argument, Kratzer (1996) also argued that Voice projects only when accusative case is assigned to the object. She cited a proposal given in Abney (1987) that nominalizing affixes like -ing attach to different syntactic levels of the extended verbal projection. Possessive gerunds result from -ing attaching to the VP. Kratzer argued that since accusative case is assigned to the object, Voice must project in possessive gerunds as shown in (31). Of gerunds result from -ing attaching to the verb. Kratzer argued that since this prevents the assignment of accusative case to the object, the projection of Voice is blocked as shown in (32).

(31) [DP Maria $_{i}\left[\right.$ 's [NP -ing [VoiceP $t_{i}[$ Voice [vp read [DP Pride and Prejudice ] ] ] ] ] ]

(32) [DP Maria ['s [NP [ -ing read ] [PP of Pride and Prejudice ] ] ] ]

Of particular interest here is the range of interpretations expressed by the genitive subjects of these gerunds. The genitive subject of a possessive gerund must express the agent relation to the event. It must be the case that Maria was the agent of the reading Pride and Prejudice event in (33). However, for of gerunds, the genitive subject may express "a general notion of relatedness of which the agent relation is but a special case" (Kratzer, 1996, 128) to the event. That is, Maria may have only attended a reading of Pride and Prejudice and we are using that to identify the event in (34).

(33) We remember Maria's reading Pride and Prejudice.

a. Maria is the Agent of the reading Pride and Prejudice event.

b. *Maria is only related to the reading Pride and Prejudice event.

(34) We remember Maria's reading of Pride and Prejudice.

a. Maria is the Agent of the reading Pride and Prejudice event.

b. Maria is only related to the reading Pride and Prejudice event. 
If stative predicates also introduce their external argument by means of Voice, we expect the same nominalization tests to detect the presence of stative Voice. (35) and (36) provide evidence for the presence of stative Voice. The possessive gerund in (35) requires Glenn Beck to be the holder of a state of hating Obama. However, the of gerund in (36), while allowing Glenn Beck to be the holder of a state of hating Obama, also allows for a general notion of relatedness of Glenn Beck to a state of hating Obama. ${ }^{17}$ Indeed, (35) would be false if Glenn Beck has no feelings at all towards Obama, while (36) would be true.

Glenn Beck's hating Obama was contagious.

a. Glenn Beck is the Holder of the hating Obama state.

b. *Glenn Beck is only related to the hating Obama state.

(36) Glenn Beck's hating of Obama was contagious.

a. Glenn Beck is the Holder of the hating Obama state.

b. Glenn Beck is only related to the hating Obama state.

Since different nominalizations can diagnose the presence of Voice in stative predicates, two further predictions arise from the hypothesis that Voice is the locus of the mapping to individuals which provides the subject its quantity and affects EIS. First, since accusative case is assigned to the object of a possessive gerund, the quantity of that object should affect EIS of the possessive gerund's subject, i.e. they should display Object Effects. Second, since accusative case is not assigned to the object of an of gerund, the quantity of that object should not affect EIS of the of gerund's subject, i.e. they should not display Object Effects. Additionally, since an of gerund does not project Voice, it cannot introduce the mapping to individuals necessary for EIS. Therefore, an of gerund should always fail to license an EIS.

While the judgments of EIS is difficult in these sentences, to the extent they are clear at all, all of the predictions are born out. As shown in (37), possessive gerunds display Object Effects, and as shown in (38), of gerunds do not display Object Effects and they fail to license an EIS. ${ }^{18}$

\footnotetext{
${ }^{17} \mathrm{~A}$ context for the second possible interpretation of these sentences is given in (i).

(i) We all know that sometimes political pundits fake their personal feelings when speaking to their base. You know, anything for the rating!

${ }^{18}$ Many thanks to E.T. Cunningham for her clear judgments on these data.
} 
(37) a. News anchors' hating these politicians was contagious.

b. News anchors' hating politicians was contagious.

(38) a. News anchors' hating of these politicians was contagious.

$(* \mathrm{EIS})$

b. News anchors' hating of politicians was contagious.

$(*$ EIS $)$

\section{Other aspectual phenomena in states}

The above analysis derives the availability of EIS from the quantity of states, however, as noted earlier there are other interpretative properties of stagelevel/individual-level states which already have a flavor of aspectuality: lifetime effects and the restriction of temporal modification. We would like this analysis to provide some insight into their behavior as well and it is these cases that I now return to.

\subsection{Lifetime effects}

As introduced above in (8a) and (8b), individual-level states often trigger lifetime effects, an inference that the subject is dead. Musan (1997), for instance, captures lifetime effects through the following conversational implicature. ${ }^{19}$ The past tense asserts that an eventuality is over, and since individual-level states hold throughout an individual's lifetime, the past tense of an individuallevel state triggers a conversational implicature: if the subject was still alive, it would be more informative to use the present tense.

A question to ask, however, is how one knows when a state is individuallevel, especially given the alternation of stage-level/individual-level behavior due to Object Effects in transitive stative predicates. Object Effects provide good evidence that this knowledge cannot be part of the verb's meaning, and it is not clear how it would arise from the verb's arguments. Instead, I have argued that the stage-level/individual-level behavior of transitive stative predicates is determined compositionally from the configuration of the verb with its particular arguments.

\footnotetext{
${ }^{19}$ The exact nature of lifetime effects continues to be debated. Magri (2009), like Musan (1997), discusses lifetime effects as a type of implicature. Kratzer (1995), however, takes lifetime effects to be an entailment from the semantics of individual-level predicates, and Mittwoch (2007) and Percus (1997) argue that lifetime effects are presuppositional.
} 
Consider how this analysis captures (12a) and (12b), repeated for convienence in (39a) and (39b). With a demonstrative object, the stative predicate in (39a) does not produce a lifetime effect. Since demonstrative objects derive quantized predicates which apply to a quantized state of the subject, I propose that lifetime effects do not arise because only some stage of the individual is put in the past. With a bare plural object, however, the stative predicate in (39b) produces a strong lifetime effect. Since bare plural objects derive homogeneous predicates which apply to homogeneous stages of the subject, i.e. the individual itself, lifetime effects arise in these cases because a homogeneous collection of the stages of the individual are put in the past. Thus, the quantity of the object not only affects EIS, but also appears to be linked to the lifetime effects on the subject.

(39) a. Those monkeys lived in this cage. $\chi_{\rightarrow}$ Those monkeys are dead.

b. Those monkeys lived in cages. $\leadsto$ Those monkeys are dead.

\subsection{Restrictions on temporal modification}

Individual-level states place tight restrictions on temporal modification. As shown above in (9a) and (9b), most temporal modifiers cannot appear with individual-level predicates. Percus (1997), however, argued that individuallevel predicates do not block all temporal modification. He proposed that examples like (9b) are blocked because they are "out-of-the-blue" utterances and must be evaluated with respect to our global context, which he suggestd is our world knowledge. World knowledge tells us that individual-level states denote properties of individuals $P$ which tend to be stable from one situation $s_{1}$ to another $s_{2}$ as defined in (40) (see also Chierchia, 1995).

(40) $P$ is tendentially stable iff $\forall s_{1}, s_{2} \in W d, x,\left[P\left(s_{1}\right)(x)=1 \& s_{2}\right.$ follows $s_{1}$ temporally \& $P\left(s_{2}\right)(x)$ is defined $] \rightarrow P\left(s_{2}\right)(x)=1$

The same question posed above for lifetime effects applies here. Given that tendential stability is a property of individual-level states, how does one know that a state is individual-level, especially since the stage-level/individuallevel behavior of transitive stative predicates is affected by Object Effects?

As with lifetime effects, I propose that the quantity of predicates derives their stability. Consider (13a) and (13b), repeated in (41a) and (41b). The demonstrative object in (41a) yields a stative predicate which is temporally 
unrestricted. Since a state composed from a demonstrative object is quantized, it likely is not temporally stable because it only applies to a quantized stage of an individual. This stage, which is spatially and temporally bounded, is unlikely to reflect anything stable about the individual. The bare plural object in (41b), however, yields a temporally restrictive stative predicate. Since the state composed from a bare plural object is homogeneous, it is likely to be temporally stable because it applies to the homogeneous collection of stages of an individual. This homogeneous collection is not spatially or temporally bounded, and thus any property it has is likely to be stable. As Percus (1997) noted, only temporal modifiers which encompass these indefinite temporal extensions, such as in (41c) can easily modify homogeneous stative predicates. Thus, the range of temporal modification for quantized stative predicates will be much wider than homogeneous stative predicates. As with lifetime effects, the quantity of the object not only affects EIS, but also the restriction on temporal modification.

(41) a. The kids liked this story yesterday.

b. \#The kids liked stories yesterday.

c. The kids liked stories throughout their childhood.

\section{Conclusions}

Like events, the interpretation of a state depends on its object. While previous theories have linked these Object Effects to topic requirements, a wider investigation finds that quantity affects EIS, suggesting that EIS is related to event composition. I proposed that a state inherits the quantity of its object, and that a subject inherits the quantity of its state. Quantized stative predicates license EIS because they apply to a quantized stage of the subject which allows for an existential inference. Homogeneous stative predicates block EIS because they apply to homogeneous stages of the subject which do not allow for an existential inference. EIS, then, is a matter of aspect that is closely related to the other aspectual behaviors of stage-level/individual-level states.

\section{References}

Abney, Steven P. 1987. The English noun phrase in its sentential aspect. Doctoral Dissertation, Cambridge, MA: MIT. 
Bhatt, Rajesh. 1999. Covert modality in non-finite contexts. Doctoral Dissertation, Philadelphia, PA: University of Pennsylvania.

Borer, Hagit. 2005a. In name only. Oxford: Oxford University Press.

Borer, Hagit. 2005b. The normal course of events. Oxford: Oxford University Press.

Carlson, Gregory N. 1977. Reference to kinds in English. Doctoral Dissertation, Amherst, MA: University of Massachusetts Amherst.

Chierchia, Gennaro. 1995. Individual-level predicates as inherent generics. In The generic book, ed. G.N. Carlson and F.J. Pelletier, 176-223. University of Chicago Press.

Chierchia, Gennaro. 1998. Reference to kinds across language. Natural language semantics 6:339-405.

Fernald, Theodore B. 1994. On the nonuniformity of the individual- and stage-level effects. Doctoral Dissertation, University of California, Santa Cruz.

Fernald, Theodore B. 2000. Predicates and temporal arguments. Oxford: Oxford University Press.

Glasbey, Sheila. 1997. I-level predicates that allow existential readings for bare plurals. In Proceedings of Semantics and Linguistic Theory, ed. A. Larson, volume 7, 169-179. Cornell University, Ithica, NY.

Heycock, Caroline. 1994. Focus projection in Japanese. In Proceedings of the Northeastern Linguistics Society, volume 24, 159-187.

Husband, E. Matthew. 2010. On the compositional nature of stativity. Doctoral Dissertation, Michigan State University.

Husband, E. Matthew. forthcoming. Some structural analogies between telicity and existential interpretation. Syntax \& Semantics.

Jäger, Gerhard. 2001. Topic-comment structure and the contrast between stage level and individual level predicates. Journal of Semantics 18:83126. 
Kiparsky, Paul. 1998. Partitive case and aspect. In The projection of arguments: Lexical and compositional factors, ed. M. Butt and W. Geuder, 265-307. CSLI, Stanford, CA.

Kratzer, Angelica. 1995. Stage-level/individual-level predicates. In The generic book, ed. G.N. Carlson and F.J. Pelletier, 125-175. University of Chicago Press.

Kratzer, Angelica. 1996. Severing the external argument from its verb. In Phrase structure and the lexicon, ed. J. Rooryck and L. Zaring, 109-137. Dordrecht, Kluwer.

Kratzer, Angelica. 2004. Telicity and the meaning of objective case. In The syntax of time, ed. J. Guéron and J. Lecarme, 389-424. The MIT Press.

Kratzer, Angelica, and Elisabeth Selkirk. 2007. Phase theory and prosodic spellout: The case of verbs. The Linguistic Review 24:93-135.

Krifka, Manfred. 1989. Nominal reference, temporal constitution and quantification in event semantics. In Semantics and contextual expression, ed. J. van Benthem R. Bartsch and P. van Emde Boas, 75-115. Foris: Dordrecht.

Krifka, Manfred. 1992. Thematic relations as links between nominal reference and temporal constitution. In Lexical matters, ed. I.A. Sag and A. Szabolcsi, 29-53. Cambridge University Press.

Krifka, Manfred. 1998. The origins of telicity. In Events and grammar, ed. S. Rothstein, 197-235. Kluwer Academic Publishers.

Lee, Chungmin. 1996. Generic sentences are topic constructions. In Reference and referent accessibility, ed. T. Fretheim and J.K. Gundel, 213-222. John Benjamins Amsterdam/Philadelphia.

Link, Godehard. 1998. Algebraic semantics in language and philosophy. Stanford, CA: CSLI Publications.

Magri, Giorgio. 2009. A theory of individual-level predicates based on blind mandatory scalar implicatures. Natural Language Semantics 17:245-297. 
Maienborn, Claudia. 2004. A pragmatic explanation of the stage level/individual level contrast in combination with locatives. In Proceedings of the western conference on linguistics, ed. B. Agbayani, V. Samiian, and B. Tucker, volume 15, 158-179. Fresno: CSU.

McNally, Louise. 1998. Stativity and theticity. In Events and grammar, ed. S. Rothstein, 293-307. Kluwer Academic Publishers.

Mittwoch, Anita. 2007. Tenses for the living and the dead: Lifetime inferences reconsidered. In Theoretical and crosslinguistic approaches to the semantics of aspect, ed. S. Rothstein, 171-187. John Benjamins Publishing Company.

Musan, Renate. 1995. On the temporal interpretation of noun phrases. Doctoral Dissertation, MIT.

Musan, Renate. 1997. Tense, predicates, and lifetime effects. Natural Language Semantics 5:271-301.

Percus, Orion J. 1997. Aspects of a. Doctoral Dissertation, MIT.

Schmitt, Christina. 1996. Aspect and the syntax of noun phrases. Doctoral Dissertation, University of Maryland.

Verkuyl, Henk J. 1972. The compositional nature of the aspects, volume 15 of Foundations of Language Supplementary Series. Dordrecht: Reidel.

Verkuyl, Henk J. 1993. A theory of aspectuality: The interaction between temporal and atemporal structure. Cambridge University Press. 